\title{
XXII. An account of some experiments on the electricity of tourmaline, and other minerals, when exposed to heat
}

James D. Forbes Esq. F.R.SS. L. \& Ed.

To cite this article: James D. Forbes Esq. F.R.SS. L. \& Ed. (1834) XXII. An account of some experiments on the electricity of tourmaline, and other minerals, when exposed to heat , Philosophical Magazine Series 3, 5:26, 133-143, DOI: 10.1080/14786443408648423

To link to this article: http://dx.doi.org/10.1080/14786443408648423

曲 Published online: 01 Jun 2009.

Submit your article to this journal $[\pi$

Џll Article views: 4

Q View related articles ¿ 
whole, than his theory of gaseous bodies and of vapours; which, had he done nothing else, would have placed him at the head of modern physical inquirers in this, and in every other country. I remain, Gentlemen, yours, \&c.

Sackville-Street, July 18, $1834 . \quad$ W. Prout.

XXII. An Account of some Experiments on the Electricity of Tourmaline, and other Minerals, when exposed to Heat. By James D. Fonbes, Esq., F.R.SS. L. \& Ed., Professor of Natural Philosophy in the University of Edinburgh*.

A LTHOUGH the phænomena of the pyro-electricity of minerals, as it has been termed, and those of the tourmaline in particular, have, after a long period of neglect, been recently studied by more than one philosopher of eminence, there is a sufficient number of undetermined or debatable points, even at the threshold of the inquiry, to yield facts of novelty and interest to those who will take the trouble to look for them.

Having during the past summer been much engaged in studying the relations of bodies to heat and electricity, I was induced, by having in my possession a considerable number of long tourmalines, to repeat and endeavour to verify some recently published experiments with this mineral. These inquiries brought out several new facts; and, with the hope of adding something to our knowledge in this curious field, I have taken this opportunity of communicating to the Society the results of some very recent experiments.

My attention was principally directed to the verification and extension of the views of M. Becquerel, whose ingenious papers published in the Annales de Chimic for 1828, give us almost the only information, with the exception of a short paper by Dr. Brewster published in 1824, which we have gained on this subject since the appearance of the works of Haïy. The undecided state in which several points of the first importance were left by the philosophers of the last century is not a little remarkable. In fact, the answer to the

* From the Transactions of the Royal Society of Edinburgh, vol. xiii. This paper was read before that Society on the 3rd of January 1832: the author explains as follows the delay in its publication:

"The publication of this paper was delayed partly under the idea of prosecuting the experiments of which it contains an account; but the author having engaged in some other researches, which apiear to him of more immediate importance, he merely prints this communication in its original form.-April 1834." 


\section{Prof. Forbes's Experiments on the Electricity of}

fundamental question of whether the tourmaline must be in the act of changing its temperature, in order to the development of electricity, may be considered to rest on the authority of Becquerel (who answered it in the affirmative), former authorities being divided upon it.

Dr. Thomson, in his work on Heat and Electricity, published in 1830, observes, that "when the tourmaline is once excited by heat, it retains its electricity for a long time, if care be taken to place it upon non-conductors. AEpinus found it electric after an interval of six hours*. He adds in a footnote, "These facts, as stated by Epinus, if accurate, seem inconsistent with the statement of Canton and Becquerel, that the electricity is only developed whilst the stone is changing its temperature." A statement of Dr. Brewster's might also appear to support the views of Epinus, and by opposing that of Becquerel, leave the question still undecided. He mentions that a slice of tourmaline cut transver'sely to the axis of the crystal, and placed on a plate of glass heated to $212^{\circ}$, adhered to it for six or eight hours, even when the glass was uppermost, the electricity of the tourmaline thus supporting its own weight.

The experiment which I am about to describe will, I think, set at rest the question, and is in fact capable of showing within a few minutes, and in a very pleasing manner, the most essential facts of the relation of the electricity to temperature. M. Becquerel found that when a crystal of tourmaline was heated to $212^{\circ}$, its electricity was inappreciable so long as the temperature remained stationary; but that when placed in a cooler medium, the intensity of the electricity was not, as might have been expected, proportional to the rapidity of the change of temperature, which of course would correspond to the period at which the temperature was bighest, but, on the contrary, arose gradually to a maximum, when the tourmaline was about half way cooled to the temperature of the apartment; then gradually diminishing, redescended to zero when it reached that point. This remarkable result M. Becquerel obtained by suspending the crystal horizontally by a fibre of silk under a glass cover, the temperature of the air in which he had the means of regulating; he then applied to the extremities of the crystal, wires from the opposite poles of a dry pile, and, counting the number of oscillations made by the tourmaline, deduced the intensity.

The form of the experiment which I have contrived, and which bears out $M$. Becquerel's conclusions, gives the same

* p. 478. † Edinburgh Journal of Science, vol, i. p. 211. 
results with great elegance and simplicity, without attempting to indicate the precise temperature of the stone at any period, which, whilst the heat of the medium in which it is placed changes, can only be by $M$. Becquerel's experiment an approximation, since the interior of the crystal must at any moment have a different temperature from its surface.

I employed a simple form of Coulomb's electrometer, which I constructed for the purpose with little difficulty. A flat-shaped bottle A B, having a wide tubulature at $\mathrm{C}$, was provided. Fitted to the neck is a tube $\mathrm{D}$, plugged at top by a cork $F$, through which passes a crooked wire $f$, for the purpose of regulating a fibre of raw silk supporting the needle of gum-lac $e$, one end of which is terminated by the disk $g$, of gilt paper. The object to be examined is introduced through the tubulature $\mathbf{C}$, the disk having previously been charged with vitreous or resinous electricity;

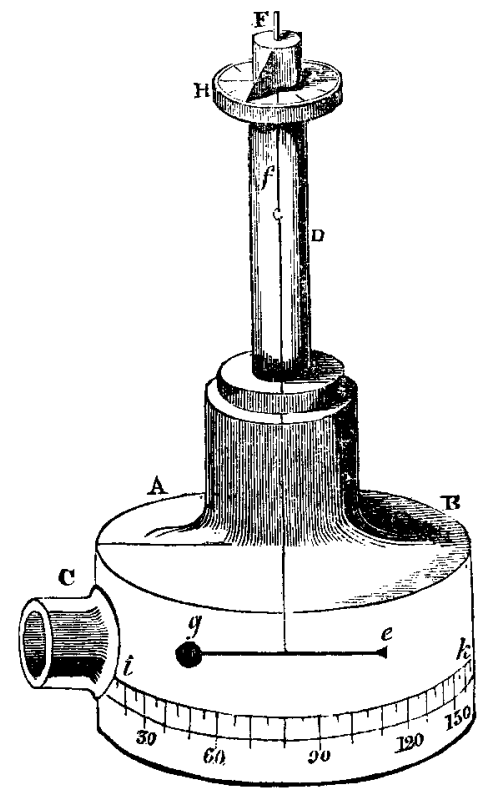
and the repulsions occasioned by the presence of the body under experiment are measured with sufficient exactness by the deviation of the needle reckoned on the divided circle of paper $i k$. I may add, that the graduated circle $\mathrm{H}$ at the top of the glass tube is employed to measure any required torsion of the silk fibre produced by causing the cork $\mathrm{F}$ to revolve. By means of this simple apparatus, I obtained results of greater accuracy than my objects generally required *.

Upon presenting to the electrometer, which is quite an insulator, an energetic crystal of tourmaline (which should not

* It is surprising that Coulomb's instrument has not been more employed in this inquiry. Becquerel seems only to have used it once, and Dr. Brewster had recourse to the laborious and unsatisfactory method of causing pyro-electric crystals to lift fragments of the Arundo Phragmites, which can give no comparative results. 
be too thin), heated to a considerable temperature, the gilt disk being charged with the same electricity as is acquired in cooling by the pole of the crystal presented, the following results appear: At first the tourmaline exerts no influence whatever; but after its temperature has begun to fall, the repulsive power is gradually developed, and the gilt disk slowly recedes as the increasing force appears : the recession becomes very minute, and at length reaches a maximum, at which the needle remains for a time stationary. Soon, however, a diminution of repulsion takes place; the disk reapproaches its original point of rest; and, if left long enough, will return to the zero point precisely opposite the crystal, which then, as at first, produces no action whatever. It is unnecessary to point out how completely this verifies M. Becquerel's views, and demonstrates that, as soon as the temperature completely ceases to change, not the minutest vestige of electricity remains, though the insulation throughout should be maintained as completely as possible. This I generally accomplish by heating and handling the crystal in glass testtubes.

With regard to Dr. Brewster's remarkable experiment, it partakes, I suspect, of a partly different class of phænomena. It occurred to me that it might, perhaps, if confirmed, be explained thus:- The slice of tourmaline may be considered, in some respect, as an electrical coating to the glass. Suppose that the tourmaline and the glass are heated together, and that the side of the slice next the pole of the crystal, assuming vitreous electricity by cooling, is next the glass. Let the other side of the glass (which we shall call the second surface) communicate with the table or any other conductor; by the law of Induction, then, it will assume resinous electricity, the first surface repelling the vitreous. Conceive the glass plate now to be insulated, we shall then have this state of things:- the surface of the tourmaline furthest from the glass, by its even excitation, is resinously electrified, for we have supposed the side which coats the first surface of the glass to be vitreous; the resinous electricity, which is insulated at the second surface of the glass, is powerfully attracting the opposite electricity of the side of the tourmaline next itself, and prevents the recombination which would otherwise take place with the electricity of the other side or pole.

Having succeeded in repeating Dr. Brewster's experiment with thin slices from a large crystal of black tourmaline, I found these hypothetical views confirmed. Having heated a slice cut transversely to the axis of the crystal, I laid it upon a plate of cold glass with the side which became vitreously 
electric during cooling uppermost; the adhesion was presently complete, so that the glass could be held with the stone suspended from its under surface. The other surface of the glass, behind the tourmaline, being then touched with a minute disk of gilt paper, insulated on a thin stick of gum-lac, and then presented to the electrometer, resinous electricity was found of considerable intensity, showing that a decomposition of electricity had actually taken place at the second surface of the glass, the resinously electric pole of the tourmaline forming the coating of its first surface, thus attracting the vitreous electricity of the second surface, and disengaging the resinous. Hence it is easy to see, that if the tourmaline remains sufficiently long warm to prevent the recombination of the electricities of its two poles, until the disengaged electricity at the second surface of the glass shall have been carried off by the air or otherwise, recombination will be prevented, and the electric state will become comparatively permanent.

The use of Coulomb's electrometer, in the manner I have already described, affords an easy and general method of comparing the electric intensities of different crystals. For by measuring the maximum deviation produced by any specimen, we obtain, wholly independent of the exact temperature, a measure of its electric power, a measure independent of time, and, as experience shows, little if at all affected by the precise heat to which the crystal has at first been raised, at least within moderate limits. That the experiment admits, even with the most ordinary attention to collateral circumstances, of considerable accuracy, I have proved by repeating the measures of the intensity of a particular specimen several times in succession. It will at once occur, that a source of fallacy must be guarded against in the loss of the electricity with which the disk of the electrometer is charged, which, as it is constantly diminishing by the contact of air, would give the intensities last measured in a series of comparative experiments too small. In favourable circumstances, and by allowing the disk to remain some time charged before the series is commenced, it is surprising how little this error amounts to. I have always, however, avoided it in practice, by repeating every series of experiments in an inverted order, by which we obtain two observations at equal distances from a mean state of electric tension, the mean of which will give strictly comparable results.

The principal application which I made of this method of observing was to attempt to discover some relation between the form and dimensions of crystals of tourmaline, and their electric power.

Third Series. Vol. 5. No. 26. Ang. 1834. 
M. Becquerel, in a second memoir on the Tourmaline, published in $1828^{\circ}$, announced the rather extraordinary circumstance, that long tourmalines did not become at all electric by heat, and that their facility of being excited was generally inversely proportional to their length. Dr. Thomson, in his work on Heat $\dagger$, mentions the former assertion, and observes that it is one which he has never had an opportunity of trying. As my experiments have been generally made with black tourmalines from Van Diemen's Land, some of which are of great length, this point early occurred to me as one deserving of investigation. As these inquiries seem at no period to have excited much attention in this country, and as of late nothing whatever has been done upon them, these observations may prove the more interesting.

The longest tourmaline employed by $M$. Becquerel was six centimetres, or 3.2 English inches, in length, with a diameter of about .08 inch. My largest tourmaline is 9.25 inches, or almost precisely the same, with a diameter little different. Instead of finding this crystal "tout à fait refractoire," as $\mathbf{M}$. Becquerel describes his, it proved uniformly susceptible of powerful excitement, under the very same treatment which I was accustomed to use towards those of smaller dimensions. The intensity too was very great, though more slowly attained than in shorter ones. Various tourmalines, between two and three inches in length, uniforrnly show great activity on being removed from the heat to which they have been exposed, and left to cool, when applied to the electroscope.

This discovery led me to some inquiry into the effect of dimension in modifying electric action. Here it is necessary to draw a distinction between the case of excitation and the intensity of the effect produced. M. Becquerel generally mentions the temperature at which electricity appeared: $\mathrm{my}$ inquiries have been directed to the maximum intensity of that electricity when excited, which is in some respects the more satisfactory information of the two. The determination of the temperature, we have already seen, is a point of great uncertainty, since every range of atoms, from the centre to the surface, must have a different temperature. Of course, for the reason, the maximum effect is the integral of an infinity of variable forces.

Amongst many experiments on different groups of crystals, I may mention the following as the best determined. Six tourmalines, all 1.3 inch long, whose thicknesses, or areas of section, were represented by the numbers $14,11,7,6$, and 4 , had

* Ann. de Chimie.

+ p. 477. 
their maximum intensities measured. Two series of experiments in a direct order, and two reversed, all gave the same order of intensity for these specimens, which, instead of bearing any direct proportion to the areas, as might have been expected, where the lengths were equal, gave the following arrangement* in the order of intensities: $1,2,5,4,3$, the areas following the natural order of the numbers. Other series being taken with sets of crystals 1.2 and 1.8 inches long, gave similar indications of irregularity + ; but the area of section has so far a general influence, that where the differences are considerable, the thickest crystal has almost universally the greatest power. The relative forces are so connected that we can hardly impute the irregularities to any general law : the differences, as I shall immediately illustrate by reference to another class of experiments, must in all probability be attributed to a variable structure in specimens of the same mineral, as well as in those of different species.

I took a crystal $1 \frac{1}{4}$ inch long, and carefully determined the intensity of its electricity, which, by a mean of three experiments, gave $45^{\circ}$ of deviation. I immediately broke it at one fourth of its length from one end: the two portions being then heated, and their intensities determined each three times, the mean of the larger portion gave a deviation of $47^{\circ}$, of the smaller $43^{\circ}$, the mean of which gives precisely the original force. As far as intensity goes, the diminution of length would not therefore appear to be favourable to the development of electricity. With a view of procuring through a larger range of dimension the influence of length alone, I selected a series of tourmalines whose sections were as nearly equal as possible, the diameter being about $\frac{1}{10}$ th inch, and one of which was the very long crystal before mentioned. This experiment was made with great care; a direct and reversed series were taken, and several of the determinations independently repeated.

* The best pair of series gave,

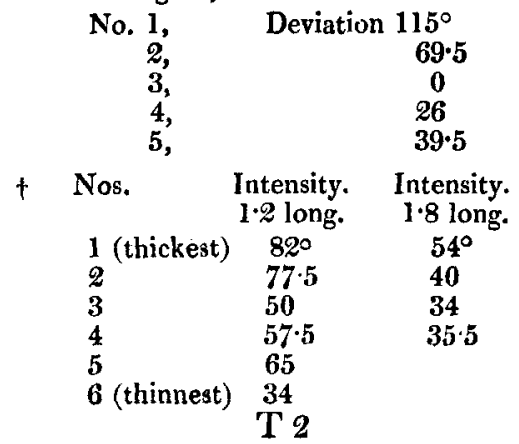


The mean deviations of the needle of the electroscope will be given in the following Table.

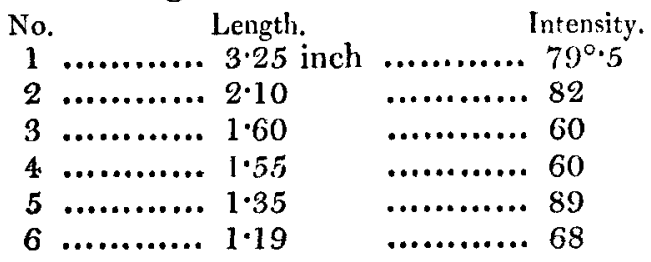

We thus see that the long crystal holds a high place among those of equal section with it, and we have at the same time an additional proof of the native irregularities of different crystals.

It is well known that the artificial arrangement which represents best the phænomena of the tourmaline, is that of a series of insulated plates of glass arranged parallel to one another, suitably coated, and with the contiguous coatings connected by tinfoil. If one end of this battery be charged from an electrical source, while the other communicates with the ground, the plates at one extremity will partake of an excess of the electricity communicated, whilst those at the other will have the opposite species in excess, and a large proportion of the range in the centre will exhibit no traces of free electricity : hence by shortening the pile (supposing the plates very numerous), no change will take place in the intensity of the free electricity, but the intensity will bear a direct relation to the surface of the plates, or the section of the pile. So far analogy supports the increase of intensity with the diameter of the tourmaline; but when we come to consider the mode of charging, it fails, and leaves us in great doubt as to whether the length of a crystal, if its structure be perfectly uniform, should have any influence or not. I have found short crystals of a considerable area, and so formed as to have a large surface, perhaps the most energetic.

The unequal temperature of the portion of any section prevents, as I have already observed, all the parts from giving a maximum intensity at once. This will diminish the total effect, but as all the parts afford the same kind of electricity, the resultant can never be null on this account. Therefore even if the irregularities of amount did not compel us to admit innate varieties of structure, or electric disposition in different specimens, stubborn facts must force us to some such conclusion. In the course of my researches I have met with a crystal of tourmaline * possessing no external irregularities of structure,

* It is No. 3. of the Series at the foot of p. 139. 
(the terminations, however, of the crystal are not preserved,) which has the singular property of presenting in cooling a vitreous pole at both ends. Having ascertained this point, I proceeded to examine the electricity of its parts by means of Coulomb's Proof-plane, by which the electricity of any portion is insulated and examined. As I expected, I found the central portion of the crystal resinously electrified. This remarkable fact is not unexampled. Haüy has recorded the case of a crystal of topaz which had a similar property, which as it is analogous to known facts in the phænomena of magnetism and of double refraction, Dr. Brewster conceived that the crystal of topaz was composed of two with the vitreous poles in contact, as in that case resinous electricity was developed at both ends. Be this as it may, the example of tourmaline which I have cited proves that the junction of the separate crystals, if such exist, may be imperceptible, and as the probability that such irregularity should exist, however caused, is in proportion to the length of the specimen, this may perhaps explain the want of excitability observed by Becquerel in very long crystals.

The phænomena of tourmaline, though entirely electric, bear so strong an affinity to those of magnetism, that the study of their relations must be considered extremely important. I have therefore one remark to make upon an experiment which Dr. Brewster thinks indicative of a "singular breach of analogy between the distribution of the pyro-electrical and magnetical forces." After observing that in the process of reducing a magnet to powder, the coercive force employed effectually destroys all trace of magnetism, he adds, that powder of tourmaline is highly electric when placed on a glass and heated, which is shown by its adhering in conglomerated masses, exhibiting the appearance of viscidity when stirred. It appears to me that this experiment does not go to show that tourmaline in a state of excitation does not lose its electricity when bruised in a mortar; indeed, such an experiment it would be impossible to perform. A tourmaline, when it is not changing its temperature, is as inert as a bar of iron before it is magnetized; the process of heating or cooling the one is precisely equivalent to that of conveying magnetism by induction or otherwise to the other. The powder of tourmaline is therefore analogous to the filings of iron, both being equally inert, till the native electricity of the former, and the native magnetism of the latter, is decomposed, when the result in both is perfectly identical.

I shall now only very briefly allude to the conclusions to which some experiments on the electricity of other minerals 
besides tourmaline have led me. I have applied Coulomb's electrometer with perfect success to the examination of topaz, boracite, and mesotype, which have all been long known to possess electrical powers. In the case of these minerals, I have been able to extend Becquerel's remarkable law of the intensity of electricity rising to a maximum, when the speed of cooling has become comparatively low, which has not before been demonstrated for any mineral except tourmaline. Topaz possesses the remarkable property of retaining its electricity long after the temperature has ceased to change; probably the decomposition being effected with greater difficulty, the recombination requires more time than in the more excitable minerals. To so great an extent does this take place, that though the maximum deviation of the needle, in one instance amounting to $115^{\circ}$, took place within a few minutes after the excited mineral was presented to the electroscope, in twenty minutes it was hardly diminished, in forty minutes it was still $95^{\circ}$, in an hour $85^{\circ}$. After a lapse of several hours it was still considerably excited ; I obtained similar results with several crystals. Probably in all minerals the difficulty of decomposition and combination increases with the mass; hence, slender crystals are most easily excited, and the effect less permanent. Keeping these facts in view, Apinus's statement that the tourmaline preserves its electricity, when insulated, for several hours, will admit of easy explanation, by supposing that he worked with large and difficultly excitable crystals, similar to this one of topaz, which had at the same time a very high degree of intensity.

With a large crystal of boracite, having about $\frac{1}{3}$ inch for the side of its cube, I obtained very analogous results. When one of its four resinous poles was presented to the electromter in a warm state, the disk slowly and regularly receded from zero as the cooling advanced, and in about ten minutes reached its maximun duration, which indicated a high degree of intensity. The diminution of electricity was very slow; in three quarters of an hour the disk had receded but a little way. A small crystal of boracite being similarly treated, the maximum was speedily gained, and the needle returned to zero in one experiment in twenty minutes, in another in half an hour. The electricity of the disk in these experiments was extremely steady.

The acicular crystals of mesotype attain with the greatest facility a high degree of electrical excitement, so much so that it required some attention to discover that the maximum inten-

* The disk during this time was of course slowly parting with its charge. 
sity was not immediately gained. It lasted a short time, and, as in the case of slender tourmalines, the needle rapidly receded, and in a short time returned to zero.

The very satisfactory results which I have obtained from all these minerals give me great confidence in the aptitude and accuracy of my simple apparatus ; and from the very considerable intensity which I find them all to possess, I expect to be able to estimate much smaller degrees of pyro-electricity in other minerals, and in artificial crystals, than have yet been attempted.

Should my first results have appeared interesting to the Society, I may perhaps at no distant time have the honour of communicating my further progress in the inquiry.

Greenhill, January 2, 1832.

\section{Proceedings of Learned Societies.}

\section{zoOLOGiCAL SOCIETY.}

1834. SPECIMENS and drawings were exhibited of a freshMarch 11.-D water Tortoise, forming part of the collection of Mr. Bell, by whom it was described as the type of a new genus, for which he proposed the name of

\section{Cxchemys.}

Sternum latum, testam dorsalem longitudine ferè æquans, integrum, solidum; testæ dorsali ligamento squamato connexum.

Cyclemys orbiculata. Cycl. testâ suborbiculari, carinata, postice dentatd, fuscd; scutis sternifluvescentibus, fusco radiatim lineatis.

Long. dorsi, 8 unc. ; lat. 7 ; alt. 3.

Emys orbiculata, Bell.

Pullus. Emys Dhor, Gray, Syn. Rept., p. 20. ?

$H a b$. in Indiâ.

Mr. Bell regards the Tortoise which he has thus characterized as supplying a link in the connecting series of the land with the freshwater families which has hitherto been wanting; and as especially valuable in the natural arrangement, by the clue which it furnishes to the correct location of the Indian forms of the genus Emys. It is, indeed, most nearly related to Emys spinosa, and on a superficial observation might almost be referred to that species; but on closer examination it is found to differ from that Tortoise, not only specifically, but generically also : its sternal bones are permanently separated from the dorsal ones, with which they are connected by means of a ligament alone, similar to that which performs the same office in Terrapene. From the Box-Tortoises, however, to which, in this point of its structure, it is so closely related, Cyclemys is altogether distinct, the whole of its sternum being entire, instead of having, as is invariably the case in Terrapene, one or more transverse divisions of the sternum itself, the lobes of which move as on a hinge. In Terr. Europa this mobility of the sternum exists in each lobe in a small degree, combined with the ligamentous connexion of the sternal to 